\title{
Determination of Pyrethroid Pesticides in Environmental Samples using Ionic Liquid Dispersive Liquid-Liquid Microextraction
}

\author{
Tong Wu, Yu Liu, Zhonghua Yang, Haixiang Gao and Zhiqiang Zhou* \\ Department of Applied Chemistry, China Agricultural University, Yuanmingyuan West Road 2, \\ Beijing 100193, P. R. China
}

\begin{abstract}
Microextração líquido-líquido dispersiva (DLLME) utilizando líquido iônico (IL) como solvente extrator foi desenvolvida com uma nova abordagem para a determinação de quatro pesticidas piretróides em amostras ambientais de água e solo. Cromatografia líquida de alto rendimento com detector de UV (HPLC-UV) foi empregada na análise cromatográfica. Este método é rápido, fácil de operar e ambientalmente correto. O solvente clorado altamente tóxico foi substituído pelo IL hexafluorofosfato de 1-hexil-3-metilimidazólio ([ $\left.\mathrm{C}_{6} \mathrm{MIM}\right]\left[\mathrm{PF}_{6}\right]$ ), para o qual elevados valores de recuperação de extração e fatores de enriquecimento foram obtidos. Os efeitos do volume de IL, tipo e volume do solvente dispersor, adição de sal, pH e tempo de extração foram investigados e otimizados. Nas condições ideais, o método mostrou boa resposta linear com valores de coeficiente de correlação $\left(\mathrm{R}^{2}\right)$ no intervalo de 0,9943 a 0,9986 . Desvio padrão relativo (RSD) variou de 3,9 a 10,1\%. Fator de enriquecimento, limite de detecção e recuperação variaram de 260 a 319, de 0,94 a $1,97 \mu \mathrm{g} \mathrm{L} \mathrm{L}^{-1}$ e de 89 a $98 \%$, respectivamente. Para amostras de água reais, RSD variou de 3,8 a 10,8\%, e recuperação de 83 a 99\%. Para análise de amostra de solo, RSD e recuperação variaram de 3,7 a $8,9 \%$ e 88 a $98 \%$, respectivamente.
\end{abstract}

Dispersive liquid-liquid microextraction (DLLME) using ionic liquid (IL) as extraction solvent was developed as a new approach for the determination of four pyrethroid pesticides in environmental water and soil samples. High-performance liquid chromatography with ultraviolet detection (HPLC-UV) was employed on chromatographic analysis. The method is rapid, easy to operate and enviromentally-friendly. The highly toxic chlorinated solvent was replaced by the IL 1-hexyl-3-methylimidazolium hexafluorophosphate $\left(\left[\mathrm{C}_{6} \mathrm{MIM}\right]\left[\mathrm{PF}_{6}\right]\right)$, in which high extraction recovery and enrichment factors were obtained. The effects of IL volume, type and volume of disperser solvent, salt addition, $\mathrm{pH}$ and extraction time were investigated and optimized. Under optimum conditions, the method showed good linear response with correlation coefficient $\left(\mathrm{R}^{2}\right)$ values in the range of 0.9943 to 0.9986 . Relative standard deviation (RSD) varied from 3.9 to $10.1 \%$. Enrichment factor, limit of detection and recovery ranged from 260 to $319,0.94$ to $1.97 \mu \mathrm{g} \mathrm{L}^{-1}$ and 89 to $98 \%$, respectively. For real water samples, RSD ranged from 3.8 to $10.8 \%$, and recovery from 83 to $99 \%$. For soil sample analysis, RSD and recovery ranged from 3.7 to $8.9 \%$ and 88 to 98 , respectively.

Keywords: ionic liquid dispersive liquid-liquid microextraction, pyrethroid pesticides, HPLC-UV, environmental sample

\section{Introduction}

Pyrethroid pesticides are synthesized through biomimetic synthesis method based on the natural pyrethrin structure. They have been widely applied in controlling agricultural and sanitary pests ${ }^{1}$ because of their excellent insecticidal activity, fast knockdown capability and

*e-mail: zqzhou@cau.edu.cn relatively low mammalian toxicity, ${ }^{2,3}$ and have been gradually taking the place of organophosphorus and carbamate pesticides. ${ }^{4-6}$ However, most pyrethroid pesticides present higher toxicity to fish compared to other organisms. ${ }^{7}$ The $\mathrm{LC}_{50}$ (median lethal concentration, $96 \mathrm{~h}$ ) for lambda-cyhalothrin, d-phenothrin and bifenthrin in rainbow trout is $0.36,2.7$ and $0.00015 \mathrm{mg} \mathrm{L}^{-1}$, respectively. Thus, their residues in rivers and lakes are hazardous to the aquatic system. ${ }^{8,9}$ Some pyrethroid pesticides accumulate 
in earthworms through continuous application. ${ }^{10}$ In field conditions, bifenthrin has a high affinity for soil. Thus, a simple and effective sample preparation method which could be applied on both liquid and solid samples is needed.

Sample preparation procedures in pesticide analysis are required to meet three goals: extraction, concentration and purification. ${ }^{11}$ Typically used sample preparation techniques include liquid-liquid extraction (LLE) and solid-phase extraction (SPE). ${ }^{12-14}$ The LLE method separates compounds based on their relative solubility in two different immiscible liquids, ${ }^{15}$ it is the extraction of a substance from one liquid phase into another liquid phase. ${ }^{16}$ LLE is time consuming and the solvent is frequently wasted. ${ }^{17,18}$ When emulsion occurs, it is difficult to separate two liquid phases. SPE has a modified performance of selectivity and is less time consuming. This method could perform the sample preparation in a batch eliminating the emulsification. However, the elution step consumes a considerable amount of solvent and the cartridge suffers from plugging. ${ }^{19}$

Several sample preparation methods have been developed based on SPE, including solid-phase microextraction (SPME), ${ }^{20,21}$ matrix solid phase extraction (MSPE) ${ }^{22,23}$ and dispersive solid-phase extraction (DSPE). ${ }^{24}$ Among these methods, SPME is the most extensively used. ${ }^{25}$ It is based on sorption and thermal desorption of analytes between matrix and fiber coating. ${ }^{26}$ SPME is a simple, solventsaving method compared with SPE. However, the fibers are comparatively expensive and have limited lifetimes..$^{16,26}$

Liquid phase microextraction including singledrop microextraction and dispersive liquid-liquid microextraction (DLLME) are developed based on LLE. ${ }^{27}$ DLLME was developed by Rezaee et al. ${ }^{28}$ in 2006 . There are three phases of liquid in the extraction procedure. The disperser is miscible with both aqueous samples and extraction solvent. The disperser is the medium for mass transfer between the two phases. Through the injection of the disperser and extractor mixture into aqueous samples, the extraction solvent is totally dispersed in the aqueous phase. The cloudy solution contains fine droplets of the formed extraction solvent. Extraction balance is then quickly achieved. DLLME has been applied in the analysis of various environmental pollutants. ${ }^{29-32}$ To adapt different matrices and achieve better extraction effects, DLLME has been modified and constantly improved. Halogenated hydrocarbons usually selected as extracting solvents in DLLME cannot be directly injected into the reverse-phase high-performance liquid chromatography (HPLC) system. ${ }^{16}$ Fan et $a .^{33}$ induced room-temperature ionic liquids (RTILs) into DLLME for the first time. RTILs are melting salt systems composed of organic cations and organic or inorganic anions. ${ }^{34}$ They are soluble in both organic and inorganic phases and compatible with the reverse-phase HPLC mobile phase. Moreover, they barely volatilize and are enviromentally friendly.

In this work, DLLME based on ionic liquid (IL) was developed for determining multiple pyrethroid pesticide residue in several environmental samples. The method was suitable for both liquid and solid samples. The main parameters in the extraction procedure were optimized. We validated the method through experiment on several environmental water and soil samples. Finally, a comparison of method performance on liquid and solid samples was made.

\section{Experimental}

Instrumentation

Chromatographic analysis was performed using Agilent 1100 HPLC system coupled with ultraviolet detector. Separation of four pyrethroid pesticides was carried out using Agilent $\mathrm{C}_{18}$ column $(250 \mathrm{~mm} \times 4.6 \mathrm{~mm}, 5 \mu \mathrm{m})$. The mixture of methanol-water (80:20 v/v) was employed as mobile phase. The injection volume and flow rate were set at $10 \mu \mathrm{L}$ and $1 \mathrm{~mL} \mathrm{~min}^{-1}$, respectively. The detection wavelength was $230 \mathrm{~nm}$. Centrifugation was performed on RJ-TD-40B (Ruijiang, China) centrifuge and $\mathrm{pH}$ measurements were carried out with Hanna pH211 benchtop $\mathrm{pH}$ meter.

\section{Reagents and materials}

Ethofenprox, lambda-cyhalothrin, d-phenothrin and bifenthrin were purchased from Agricultural Environmental Protection Institution (Tianjin, China). Methanol, acetonitrile and acetone employed in the experiment were from Damao Chemical Reagent Factory (Tianjin, China). All the reagents are of HPLC-grade. 1-Hexyl3-methylimidazolium hexafluorophosphate [C6MIM][PF6] was purchased from Lanzhou Institute of Chemical Physics, Chinese Academy of Sciences. Hydrochloric acid $(\mathrm{HCl})$ and sodium chloride $(\mathrm{NaCl})$ were from Sinopharm Chemical Reagent Co. (Beijing, China).

Stock standard solutions of $1000 \mathrm{mg} \mathrm{L}^{-1}$ for each analyte were prepared in methanol. The working solutions were obtained by adding appropriate volume of standard solution into pure water.

Environmental water samples were collected from the local area of Beijing. River water was collected from Xiaoqing River. Reservoir water was collected from Shangzhuang reservoir. Tap water was obtained from the laboratory. Soil samples were collected from the foot of 
the Baiwang Mountain. The water and soil samples were found to be free of target analytes.

\section{Procedures}

River and reservoir water volumes were filtered through a $0.45 \mu \mathrm{m}$ membrane before the DLLME procedure. Soil samples were air-dried at room temperature and sieved to a grain size of $2 \mathrm{~mm}$. An amount of $5 \mathrm{~g}$ spiked soil was added to $10 \mathrm{~mL}$ methanol. The mixture was vortexed for $5 \mathrm{~min}$ and then centrifuged at $4000 \mathrm{rpm}$ for $5 \mathrm{~min}$. The $5 \mathrm{~mL}$ upper solution was placed in a $10 \mathrm{~mL}$ screw-cap glass tube with a conical bottom. The solution was employed as a disperser in the DLLME procedure.

For DLLME, a $5 \mathrm{~mL}$ aliquot of water sample was placed in a $10 \mathrm{~mL}$ screw-cap glass tube with a conical bottom. Next, $0.046 \mathrm{~mL}\left[\mathrm{C}_{6} \mathrm{MIM}\right]\left[\mathrm{PF}_{6}\right]$ and $0.60 \mathrm{~mL}$ methanol were placed in another glass tube with a conical bottom. A $1 \mathrm{~mL}$ syringe was used to withdraw and inject methanol in the tube several times until the complete mix of IL and methanol. The mixture was then totally withdrawn and rapidly injected into the water sample. The glass tube was gently shaken by hand. A cloudy solution was formed and extraction balance was attained. Analytes were extracted from the sample solution into the IL $\left[\mathrm{C}_{6} \mathrm{MIM}\right]\left[\mathrm{PF}_{6}\right]$. After centrifugation at $4000 \mathrm{rpm}$ for $5 \mathrm{~min}$, the IL phase was sedimented at the bottom of the glass tube. The upper aqueous layer was completely removed by a syringe. In preliminary experiment, it was observed that when acetonitrile was employed as disperser solvent, there was a bigger amount of IL sedimented at the bottom of the glass tube than that when methanol was employed as disperser solvent. This may be explained that acetonitrile has a better effect on dissolving [C6MIM][PF6] than methanol. It was also found that $\left[\mathrm{C}_{6} \mathrm{MIM}\right]\left[\mathrm{PF}_{6}\right]$ dissolved faster and easier in acetonitrile than in methanol. Thus, $50 \mu \mathrm{L}$ acetonitrile was employed to dissolve $\left[\mathrm{C}_{6} \mathrm{MIM}\right]\left[\mathrm{PF}_{6}\right]$. For analysis, $10 \mu \mathrm{L}$ of the mixture were injected into the HPLC system.

\section{Results and Discussion}

\section{Optimization of IL-DLLME procedure}

\section{Effect of IL volume}

The amount of extraction solvent is a very important factor that affects the yields of DLLME. Too little IL may lead to a minute amount of sediment phase, which is difficult to operate and results in bad repeatability. In contrast, a too large amount of IL brings about lower enrichment factor. To study the effect of IL volume on the extraction efficiency, solutions containing different amounts of IL and a constant volume of methanol were tested in the DLLME procedure. Figure 1 depicts the relationship between extraction efficiency and IL volume. As the volume of $\left[\mathrm{C}_{6} \mathrm{MIM}\right]\left[\mathrm{PF}_{6}\right]$ increased from 0.031 to $0.046 \mathrm{~mL}$, the extraction recovery increased. However, by increasing the IL volume from 0.046 to $0.077 \mathrm{~mL}$, the recovery remained practically constant whereas the enrichment factor decreased. Based on the results, $0.046 \mathrm{~mL}$ was chosen as the optimum volume of extraction solvent.

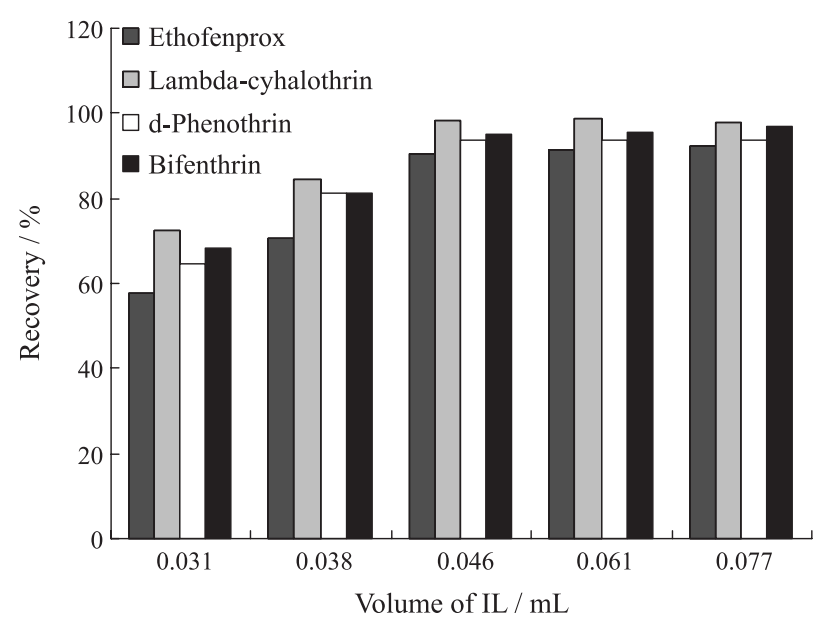

Figure 1. Effect of $\left[\mathrm{C}_{6} \mathrm{MIM}\right]\left[\mathrm{PF}_{6}\right]$ volume on extraction recoveries of four pesticides. Extraction conditions: sample volume of $5.00 \mathrm{~mL}$, spike level of $50 \mu \mathrm{g} \mathrm{L}{ }^{-1}$, extraction solvent $\left[\mathrm{C}_{6} \mathrm{MIM}\right]\left[\mathrm{PF}_{6}\right]$ and disperser solvent volume of $0.60 \mathrm{~mL}$ methanol.

\section{Selection of disperser solvent and its volume}

The type and volume of the disperser greatly influence the extraction performance. The disperser solvent is the medium between the aqueous phase and the extraction solvent. Thus, the key point for selecting the disperser solvent is its relative miscibility with the two phases. The effects of methanol, acetonitrile and acetone were investigated. The water was spiked with $50 \mu \mathrm{g} \mathrm{L}^{-1}$ each of the four pyrethroid pesticides. Afterward, $0.60 \mathrm{~mL}$ of each disperser solvent containing $0.046 \mathrm{~mL}\left[\mathrm{C}_{6} \mathrm{MIM}\right]\left[\mathrm{PF}_{6}\right]$ was employed in the extraction procedure. The result is shown in Figure 2. When acetonitrile was used as disperser solvent, IL was rarely sedimented at the bottom of the glass tube after centrifugation and the recovery was quite low. When methanol was used as disperser solvent, the recoveries were generally better than those generated using acetone, except for the recovery of lambda-cyhalothrin, which was slightly lower. Therefore, methanol was chosen as disperser solvent.

The variation of the volume of disperser solvent may also cause changes in the recovery. To investigate this parameter, extraction was performed using different volumes $(0.2-0.8 \mathrm{~mL})$ of methanol containing $0.046 \mathrm{~mL}$ IL. The results are shown 


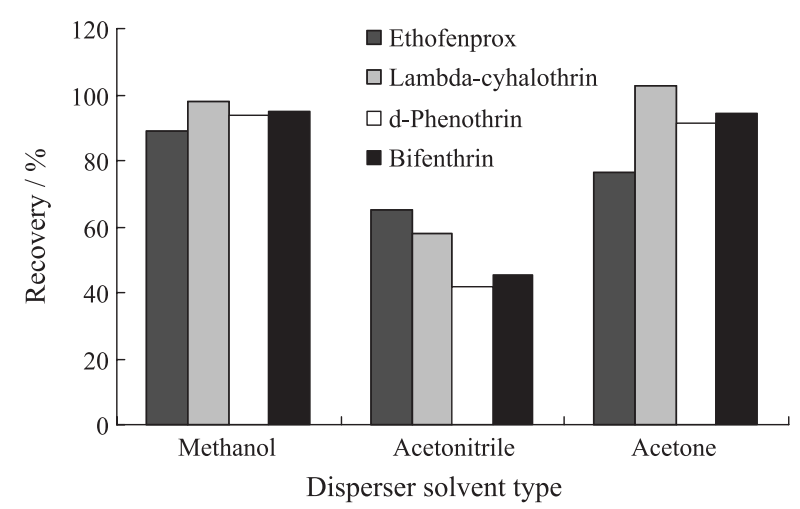

Figure 2. Effect of disperser solvent on extraction recoveries of four pesticides. Extraction conditions: sample volume of $5.00 \mathrm{~mL}$, spike level of $50 \mu \mathrm{g} \mathrm{L}^{-1}$, disperser solvent (methanol, acetonitrile and acetone) volume of $0.60 \mathrm{~mL}$ and extraction solvent $\left(\left[\mathrm{C}_{6} \mathrm{MIM}\right]\left[\mathrm{PF}_{6}\right]\right)$ volume of $0.046 \mathrm{~mL}$.

in Figure 3. By increasing the volume of disperser solvent from 0.20 to $0.60 \mathrm{~mL}$, the recovery increased. The increase in the disperser volume brought about the decrease of the sediment phase volume. Thus, the enrichment factor also increased. The best recovery was obtained when $0.60 \mathrm{~mL}$ methanol was employed, thus $0.60 \mathrm{~mL}$ was used as the optimum volume for disperser solvent.

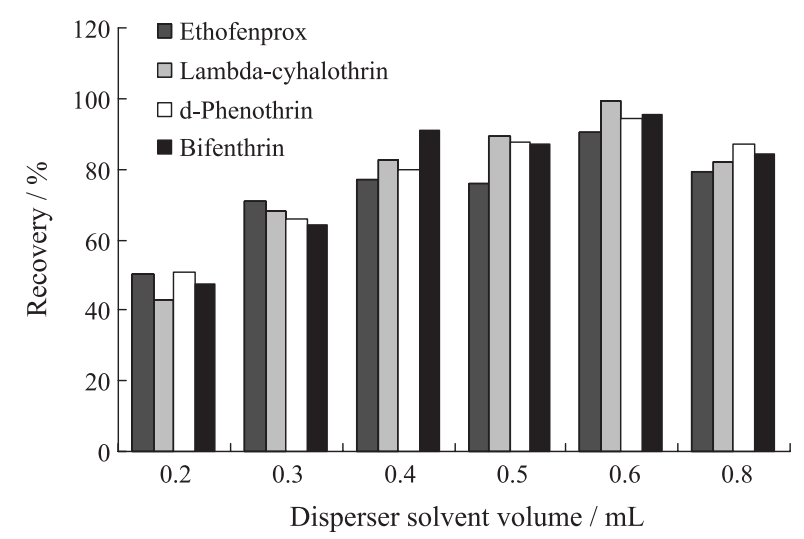

Figure 3. Effect of methanol volume on extraction recoveries of four pesticides. Extraction conditions: sample volume of $5.00 \mathrm{~mL}$, spike level of $50 \mu \mathrm{g} \mathrm{L}-1$, extraction solvent ([C $\left.\left.\mathrm{C}_{6} \mathrm{MIM}\right]\left[\mathrm{PF}_{6}\right]\right)$ volume of $0.046 \mathrm{~mL}$ and methanol as disperser solvent.

\section{Effect of salt addition}

The effect of salting out may help in the extraction procedure. To study the effect of salt addition, the extraction was performed by adding sodium chloride ranging from 1 to $5 \%$ into water. From Figure 4, the addition of salt caused a decrease in the recovery. The addition of more salt leads to a continuous drop in the recovery because the addition of $\mathrm{NaCl}$ enhances the solubility of both analytes and IL in water. A decrease in the settled phase volume can be observed with the increase in the $\mathrm{NaCl}$ concentration. No salt addition was adopted in further studies.

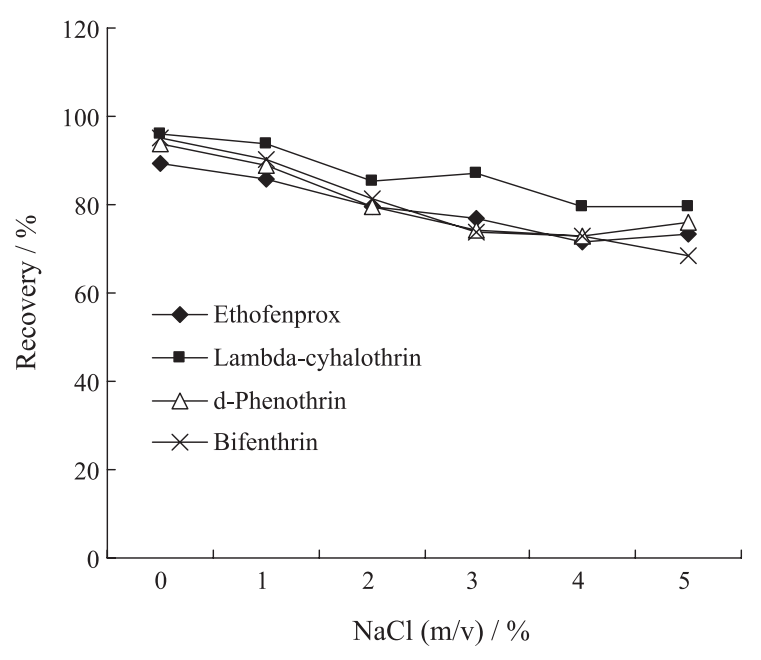

Figure 4. Effect of salt addition on extraction recoveries of four pesticides. Extraction conditions: sample volume of $5.00 \mathrm{~mL}$, spike level of $50 \mu \mathrm{g} \mathrm{L}^{-1}$, extraction solvent $\left(\left[\mathrm{C}_{6} \mathrm{MIM}\right]\left[\mathrm{PF}_{6}\right]\right)$ volume of $0.046 \mathrm{~mL}$ and disperser solvent volume of $0.60 \mathrm{~mL}$ methanol.

\section{Effect of sample solution $\mathrm{pH}$}

Sample solution $\mathrm{pH}$ is another factor that may affect the DLLME recovery. The effect of this parameter was investigated over the $\mathrm{pH}$ range of 1-7 using $\mathrm{HCl}$. The results are shown in Figure 5. When $\mathrm{pH}$ changed from 7 to 1, the recovery decreased for all four pesticides. Therefore, the acid addition was not adopted, which further simplified the extraction procedure.

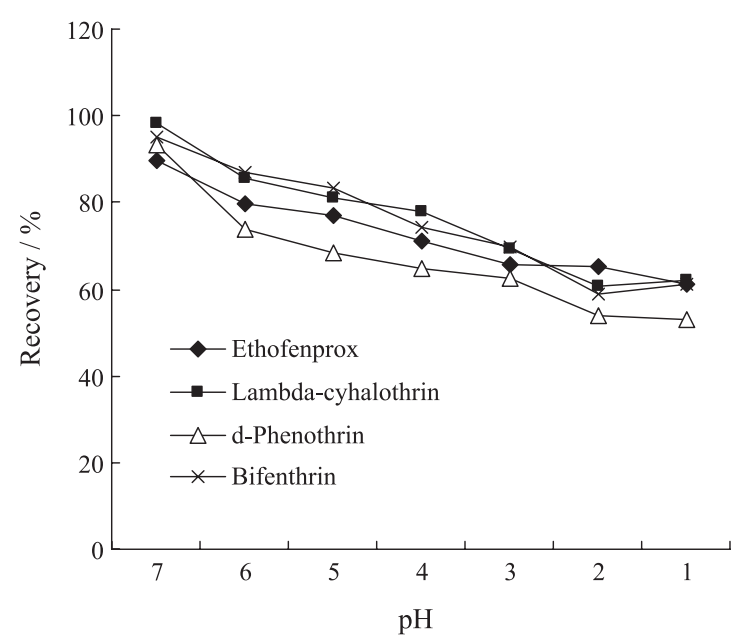

Figure 5. Effect of sample $\mathrm{pH}$ on extraction recoveries of four pesticides. Extraction conditions: sample volume of $5.00 \mathrm{~mL}$, spike level of $50 \mu \mathrm{g} \mathrm{L}^{-1}$, extraction solvent $\left(\left[\mathrm{C}_{6} \mathrm{MIM}\right]\left[\mathrm{PF}_{6}\right]\right)$ volume of $0.046 \mathrm{~mL}$ and disperser solvent volume of $0.60 \mathrm{~mL}$ methanol.

\section{Effect of extraction time}

For most extraction procedures, the extraction time is a crucial factor that affects the recovery. All kinds of extractions require a certain time to obtain the equilibrium of analytes transferring between the sample solution and 
the extraction solvent. One of the advantages of DLLME is that it only requires a relatively short time to obtain the extraction equilibrium. The extraction time starts from the injection of disperser solvent and IL to the start of the centrifugation time. In the current research, the effect of extraction time within the range of 1-20 min was studied. Based on Figure 6, the best recovery could be obtained in 5 min, which means the extraction obtained the equilibrium within the first $5 \mathrm{~min}$. Thus, it was selected $5 \mathrm{~min}$ as the extraction time, which is also generally required in simultaneous pretreatment for batches of samples.

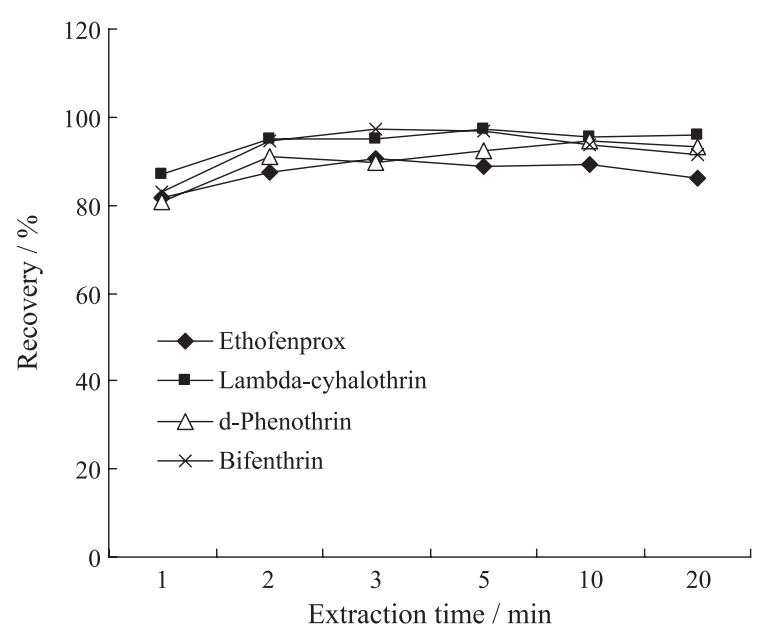

Figure 6. Effect of extraction time on extraction recoveries of four pesticides. Extraction conditions: sample volume of $5.00 \mathrm{~mL}$, spike level of $50 \mu \mathrm{g} \mathrm{L}{ }^{-1}$, extraction solvent ([C $\left.\left.\mathrm{C}_{6} \mathrm{MIM}\right]\left[\mathrm{PF}_{6}\right]\right)$ volume of $0.046 \mathrm{~mL}$ and disperser solvent volume of $0.60 \mathrm{~mL}$ methanol.

\section{Method validation}

\section{Water samples}

After IL-DLLME optimization, the linearity, repeatability, limit of detection (LOD) and enrichment factor were investigated using the optimum parameters. The linearity was observed over the concentration range of 2-200 $\mu \mathrm{g} \mathrm{L}^{-1}$ for the four pesticides. The correlation coefficients were from 0.9943 to 0.9986 . The repeatability was investigated by extracting purified water spiked at $5 \mu \mathrm{g} \mathrm{L}^{-1}$ from the five replicates. The relative standard deviations (RSD) were calculated and the results were 6.2, 3.9, 5.6 and $10.1 \%$. The enrichment factor was defined as the ratio of analyte concentration between IL sediment and initial water sample. The enrichment factors for the four pesticides were from 260 to 319. LOD ranged from 0.94 to $1.97 \mu \mathrm{g} \mathrm{L}^{-1}$, obtained at a ratio of signal to noise $(\mathrm{S} / \mathrm{N}=3)$. The extraction recoveries of ethofenprox, lambda-cyhalothrin, d-phenothrin and bifenthrin were $89,98,93$ and $95 \%$, respectively. The results are shown in Table 1.

\section{Soil samples}

When the proposed method was applied on the soil samples, the analyte existed in the organic solvent (disperser) instead of in the purified water before the DLLME procedure. Thus, a comparison of extraction effect was made between extracting from organic solvent and extracting from purified water. In group A, the purified water was spiked at $50 \mu \mathrm{g} \mathrm{L}{ }^{-1}$. In group B, the disperser (methanol) was spiked at $417 \mu \mathrm{g} \mathrm{L} \mathrm{L}^{-1}$, which means the total amount of analyte in the mixture was exactly the same. There were three replicates for each group. From Figure 7, the difference was not significant. This also supported the validity of the application of the proposed method on soil samples.

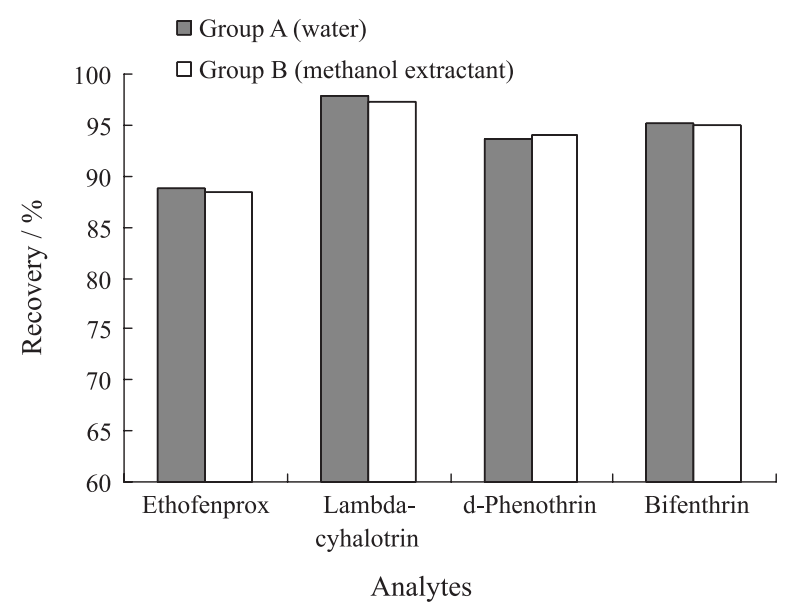

Figure 7. Comparison of extraction effect between extracting from water and extracting from organic solvent (methanol). Extraction conditions: water sample volume of $5.00 \mathrm{~mL}$, extraction solvent $\left(\left[\mathrm{C}_{6} \mathrm{MIM}\right]\left[\mathrm{PF}_{6}\right]\right)$ volume of $0.046 \mathrm{~mL}$ and disperser solvent volume of $0.60 \mathrm{~mL}$ methanol.

Table 1. Analytical performance data for the proposed method

\begin{tabular}{lcccccc}
\hline Pesticide & $\begin{array}{c}\text { Linearity / } \\
\left(\mu \mathrm{g} \mathrm{L}^{-1}\right)\end{array}$ & $\begin{array}{c}\text { Correlation } \\
\text { coefficient }\left(\mathrm{R}^{2}\right)\end{array}$ & $\mathrm{RSD}^{\mathrm{a}} / \%$ & $\begin{array}{c}\text { Enrichment } \\
\text { factors }\end{array}$ & $\begin{array}{c}\mathrm{LOD}^{\mathrm{b}} / \\
\left(\mu \mathrm{g} \mathrm{L}^{-1}\right)\end{array}$ & \begin{tabular}{c} 
Recovery / \% \\
\hline Ethofenprox
\end{tabular} \\
\hline Lambda-cyhalothrin & $2-200$ & 0.9974 & 6.2 & 282 & 1.19 & 89 \\
d-Phenothrin & $2-200$ & 0.9960 & 3.9 & 319 & 0.94 & 98 \\
Bifenthrin & $2-200$ & 0.9943 & 5.6 & 291 & 1.12 & 93 \\
\hline
\end{tabular}

${ }^{\mathrm{a}}$ Data calculated from 5 replicates spiked with $5 \mu \mathrm{g} \mathrm{L}{ }^{-1}$ of each pesticide; bdata calculated from aqueous sample spiked with $5 \mu \mathrm{g} \mathrm{L}{ }^{-1}$ of each pesticide, $\mathrm{S} / \mathrm{N}=3$ (ratio of signal to noise); RSD: relative standard deviation; LOD: limit of detection. 
Table 2. Recoveries obtained in the determination of pyrethroid pesticides in soil samples

\begin{tabular}{|c|c|c|c|c|c|}
\hline Pesticide & Equation & $\begin{array}{c}\text { Correlation coefficient } \\
\qquad\left(\mathrm{R}^{2}\right)\end{array}$ & $\mathrm{RSD}^{\mathrm{a}} / \%$ & $\mathrm{LOD}^{\mathrm{b}} /\left(\mu \mathrm{g} \mathrm{L}{ }^{-1}\right)$ & Recovery / \% \\
\hline Ethofenprox & $y=1.496 x-3.761$ & 0.9984 & 3.7 & 14.91 & 92 \\
\hline Lambda-cyhalothrin & $y=1.296 x+8.001$ & 0.9960 & 7.7 & 13.11 & 98 \\
\hline d-Phenothrin & $y=1.384 x-1.792$ & 0.9995 & 7.8 & 10.38 & 88 \\
\hline Bifenthrin & $y=1.33 x-2.802$ & 0.9961 & 8.9 & 15.56 & 94 \\
\hline
\end{tabular}

${ }^{a}$ Data calculated from 5 replicates spiked with $50 \mu \mathrm{g} \mathrm{L}^{-1}$ of each pesticide; bdata calculated from soil sample spiked with $50 \mu \mathrm{g} \mathrm{L}{ }^{-1}$ of each pesticide, $\mathrm{S} / \mathrm{N}=3$ (ratio of signal to noise); RSD: relative standard deviation; LOD: limit of detection.

Table 3. Recoveries obtained in the determination of pyrethroid pesticides in three real water samples

\begin{tabular}{|c|c|c|c|c|c|c|c|}
\hline \multirow{2}{*}{ Pesticide } & \multirow{2}{*}{$\begin{array}{l}\text { Spiked level / } \\
\left(\mu \mathrm{g} \mathrm{L}^{-1}\right)\end{array}$} & \multicolumn{2}{|c|}{ Tap water } & \multicolumn{2}{|c|}{ Reservoir water } & \multicolumn{2}{|c|}{ River water } \\
\hline & & Recovery / \% & $\mathrm{RSD} / \%$ & Recovery / \% & $\mathrm{RSD} / \%$ & Recovery / \% & $\mathrm{RSD} / \%$ \\
\hline \multirow[t]{2}{*}{ Ethofenprox } & 5 & 89 & 6.9 & 91 & 7.3 & 89 & 7.1 \\
\hline & 20 & 86 & 5.8 & 83 & 6.0 & 88 & 5.8 \\
\hline \multirow[t]{2}{*}{ Lambda-cyhalothrin } & 5 & 98 & 4.2 & 99 & 4.8 & 95 & 4.8 \\
\hline & 20 & 96 & 3.9 & 94 & 3.8 & 98 & 4.3 \\
\hline \multirow[t]{2}{*}{ d-Phenothrin } & 5 & 91 & 6.6 & 93 & 6.9 & 94 & 5.9 \\
\hline & 20 & 89 & 5.7 & 91 & 5.1 & 96 & 6.4 \\
\hline \multirow[t]{2}{*}{ Bifenthrin } & 5 & 93 & 10.6 & 96 & 9.7 & 91 & 10.8 \\
\hline & 20 & 88 & 8.9 & 89 & 10.5 & 95 & 9.4 \\
\hline
\end{tabular}

RSD: relative standard deviation.

The linearity, RSD, LOD and recovery were also investigated. The results are listed in Table 2 . The linearity was studied in the range of 50-2000 $\mathrm{g} \mathrm{L}^{-1}$. The correlation coefficients were from 0.9960 to 0.9995 . RSD ranged from 3.7 to $8.9 \%$. LOD and recoveries were from 10.38 to 15.56 and 88 to 98 , respectively.

\section{Application of the method}

\section{Water sample analysis}

The proposed method was used to analyze three kinds of water samples (tap water, reservoir water and river water) to evaluate their applicability. The water samples were spiked at a concentration level of 5 and $20 \mu \mathrm{g} \mathrm{L}^{-1}$, and extracted under optimized conditions. Each extraction was performed five times. The extraction recovery and RSD were calculated. The result is shown in Table 3. The recoveries ranged from 83 to $99 \%$ and RSD from 3.8 to $10.8 \%$.

\section{Soil samples analysis}

The effects of extraction on soil were previously described. From the data in Table 2, the recoveries were rather good. Moreover, no significant difference was observed in the extractions from groups A and B. This implies that IL can also extract the target analyte from the organic solvent when water plays the role of disperser.

\section{Conclusions}

IL-DLLME coupled with HPLC-UV was developed to analyze four pyrethroid pesticides in water and soil. The method is simple and fast. The use of IL makes the method benign to the environment and less harmful to humans. Extraction, concentration and purification were combined in one step. The method is highly efficient, and thus labor is reduced. The application of the method was extended to soil samples, whereas few DLLME were used on solid samples. The recoveries were good in both water and solid sample analysis. Thus, the method proposed in this article is a good approach for the analysis of pyrethroid pesticides in environmental samples.

\section{Acknowledgements}

The financial supports for this research provided by Natural Science Foundation of P. R. China (20877100), Program for New Century Excellent Talents in University and A Foundation for the Author of National Excellent Doctoral Dissertation of P. R. China are gratefully acknowledged.

\section{References}

1. Ansari, R. A.; Rahman, S.; Kaur, M.; Anjum, S.; Raisuddin, S.; Ecotoxicol. Environ. Saf. 2011, 74, 150. 
2. Chuang, J. C.; Wilson, N. K.; J. Environ. Sci. Health., Part B 2011, 46, 41.

3. López-López, T.; Gil-Garcia, M. D.; Martínez-Vidal, J. L.; Martinez-Galera, M.; Anal. Chim. Acta 2001, 447, 101.

4. Hartnik, T.; Sverdrup, L. E.; Jensen, J.; Environ. Toxicol. Chem. 2009, 27, 1408.

5. Solomon, K. R.; Giddings, J. M.; Maund, S. J.; Environ. Toxicol. Chem. 2001, 20, 652.

6. Moore, A.; Waring, C. P.; Aquat. Toxicol. 2001, 52, 1.

7. Rawn, D. F. K.; Judge, J.; Roscoe, V.; Anal. Bioanal. Chem. 2010, 397, 2525.

8. Saha, S.; Kaviraj, A.; Bull. Environ. Contam. Toxicol. 2008, 80, 49.

9. Hartnik, T.; Styrishave, B.; J. Agric. Food Chem. 2008, 56, 11057.

10. Tripathi, G.; Kachhwaha, N.; Dabi, I.; Pestic. Biochem. Physiol. 2010, 98, 333.

11. Bidari, A.; Ganjali, M. R.; Norouzi, P.; Hosseini, M. R. M.; Assadi, Y.; Food Chem. 2011, 126, 1840.

12. Jia, C. H.; Zhu, X. D.; Zhao, E. C.; Yu, P. Z.; He, M.; Chen, L.; Chromatographia 2010, 72, 1219.

13. Ahmed, F. E.; TrAC, Trends Anal. Chem. 2001, 20, 649.

14. Karazafiris, E.; Menkissoglu-Spiroudi, U.; Thrasyvoulou, A.; J. Chromatogr., A 2008, 1209, 17.

15. Wang, L. H.; Mei Y. H.; Wang, F.; Liu, X. S.; Chen, Y.; Sep. Purif. Technol. 2011, 77, 397.

16. Rezaee, M.; Yamini, Y.; Faraji, M.; J. Chromatogr., A 2010, 1217, 2342.

17. Wu, Q. H.; Zhou, X.; Li, Y. M.; Zang, X. H.; Wang, C.; Wang, Z.; Anal. Bioanal. Chem. 2009, 393, 1755.

18. Fu, L. Y.; Liu, X. J.; Hu, J.; Zhao, X. N.; Wang, H. L.; Wang, X. D.; Anal. Chim. Acta 2009, 632, 289.

19. Zhou, Q. X.; Bai, H. H.; Xie, G. H.; Xiao, J. P.; J. Chromatogr., A 2008, 1188, 148.
20. Casas, V.; Llompart, M.; Garcia-Jares, C.; Cela, R.; Dagnac, T.; Anal. Bioanal. Chem. 2007, 387, 1841.

21. You, J.; Michael, J. L.; Int. J. Environ. Anal. Chem. 2006, 86, 381.

22. Cheng, J. H.; Liu, M.; Yu, Y.; Wang, X. P.; Zhang, H. Q.; Ding, L.; Jin, H. Y.; Meat Sci. 2009, 82, 407.

23. Fernandez-Alvarez, M.; Llompart, M.; Lamas, J. P.; Lores, M.; Garcia-Jares, C.; Cela, R.; Dagnac, T.; J. Chromatogr., A 2009, 1216,2832

24. Dagnac, T.; Garcia-Chao, M.; Pulleiro, P.; Garcia-Jares, C.; Llompart, M.; J. Chromatogr., A 2009, 1216, 3702.

25. Jeannot, M. A.; Cantwell, F. F.; Anal. Chem. 1997, 69, 2935.

26. Xiong, J.; Hu, B.; J. Chromatogr., A 2008, 1193, 7.

27. Wu, Q. H.; Wang, C.; Liu, Z. M.; Wu, C. X.; Zeng, X.; Wen, J. L.; Wang, Z.; J. Chromatogr., A 2009, 1216, 5504.

28. Rezaee, M.; Assadi, Y.; Hosseini, M. R. M.; Aghaee, E.; Ahmadi, F.; Berijani, S.; J. Chromatogr., A 2006, 1116, 1.

29. Herrera-Herrera,A.V.; Asensio-Ramos, M.; Hernández-Borges, J.; Rodríguez-Delgado, M. A.; TrAC, Trends Anal. Chem. 2010, 29,728 .

30. Hu, J.; Li, Y. Y.; Zhang, W.; Wang, H. L.; Huang, C. J.; Zhang, M. H.; Wang, X. D.; J. Sep. Sci. 2009, 32, 2103.

31. Zhou, Q. X.; Pang, L.; Xiao, J. P.; J. Chromatogr., A 2009, 1216, 6680.

32. Faraji, H.; Helalizadeh, M.; Int. J. Environ. Anal. Chem. 2010, $90,869$.

33. Fan, Y. C.; Hu, Z. L.; Chen, M. L.; Tu, C. S.; Zhu, Y.; Chin. Chem. Lett. 2008, 19, 985.

34. Liu, Y.; Zhao, E. C.; Zhu, W. T.; Gao, H. X.; Zhou, Z. Q.; J. Chromatogr., A 2009, 1216, 885.

Submitted: November 7, 2011

Published online: June 26, 2012 